\title{
ESTUDO GEOAMBIENTAL DO MUNICÍPIO DE BOM JARDIM - RJ, COM SUPORTE DE GEOTECNOLOGIAS: SUBSÍDIOS AO PLANEJAMENTO DE PAISAGENS RURAIS MONTANHOSAS
}

\section{Geoenvironmental study of municipality of Bom Jardim - RJ, with support of geographical information system: subsidies to planning of mountainous rural landscapes}

Braz Calderano Filho

Doutorando em Geologia

Universidade Federal do Rio de Janeiro/UFRJ

Embrapa Solos/RJ

Rio de Janeiro/RJ - Brasil

bccalder@gmail.com

Helena Polivanov

Prof ${ }^{\text {a }}$. Adjunta do Departamento de Geologia

Universidade Federal do Rio de Janeiro/UFRJ

Rio de Janeiro/RJ - Brasil polivanov@gmail.com

Antônio José Teixeira Guerra

Prof. Adjunto do Departamento de Geografia Universidade Federal do Rio de Janeiro/UFRJ

Rio de Janeiro/RJ - Brasil antoniotguerra@gmail.com

Cesar da Silva Chagas

Universidade Federal do Rio de Janeiro/UFRJ

Rio de Janeiro/RJ - Brasil cesar@cnps.embrapa.br

Waldir de Carvalho Júnior Federal do Rio de Janeiro/UFRJ

Rio de Janeiro/RJ - Brasil waldir@cnps.embrapa.br

Sebastião Barreiros Calderano

Federal do Rio de Janeiro/UFRJ

Rio de Janeiro/RJ - Brasil sebast@cnps.embrapa.br

Artigo recebido para publicação em 05/11/2009 e aceito para publicação em 22/02/2010 
Estudo Geoambiental do Município de Bom Jardim - RJ, com Suporte de Geotecnologias: Subsídios ao Planejamento de Paisagens Rurais Montanhosas

Braz Calderano Filho, Helena Polivanov, Antônio José Teixeira Guerra, Cesar da Silva Chagas, Waldir de Carvalho Júnior, Sebastião Barreiros Calderano

RESUMO: Oestudo teve o objetivo de produzir informações físico-bióticas dos elementos componentes da paisagem, visando fornecer subsidios para o planejamento geoambiental de paisagens rurais montanhosas na serra dos Órgãos, ocupadas com agricultura familiar. Com suporte de geotecnologias, o trabalho combinou técnicas de mapeamento digital, produtos de sensoriamento remoto, sistema de informação geográfica (SIG) e modelo digital de elevação (MDE), buscando otimizar os mapeamentos temáticos no campo e facilitar a geração de mapas derivados e interpretações úteis ao planejamento da área. Os procedimentos utilizados envolveram a geração de bancos de dados digitais no SIG e a geração de dados básicos no campo, através de mapeamentos temáticos do meio físico, que foram associadas com informações socioeconômicas, de pluviosidade e de áreas protegidas por legislação especifica ou reservas existentes, constituindo assim, um conjunto de informações agro-socioambientais em meio digital. Os resultados produzidos permitiram discriminar e caracterizar aspectos físicos e ecológicos dos elementos componentes da paisagem, contribuindo para a melhor compreensão dos recursos ambientais com suas potencialidades e limitações, além de contribuir para planejamento geoambiental e elaboração do plano de manejo conservacionista da área.

Palavras-chaves: Diagnóstico geoambiental. Modelo digital de elevação. Geoprocessamento. Manejo do solo e água.

ABSTRACT: This research aims to produce biophysical information of the landscape components, with the objective to supply a background to the environmental planning of the rural areas in the mountainous region of Serra dos Orgaos, under family agriculture. With support of geographical information system, this research has combined digital mapping techniques based on remote sensing with digital elevation model (DEM), aiming to optimize the field thematic maps and to facilitate the generation of maps and useful interpretations, in order to use them for planning purposes. The procedures used in this research took into consideration the creation of a database based on digital data from the GIS, and the generation of basic data obtained in the field, through environmental thematic maps associated with socio-economic information, rainfall data and protected areas, based on legislation, creating therefore, a set of agro-socio-environmental information in a digital system. The results allow us to discriminate and to characterize the physical and ecological landscape elements, contributing to a better understanding of the environmental resources and their potentialities and limitations, besides to contribute to the environmental planning and to create a conservationist managing plan to the research area.

Key words: Environmental assessment. Digital elevation model. Geoprocessing. Soil and water management.

\section{INTRODUÇÃO}

Localizado na região serrana do estado do Rio de Janeiro, o município de Bom Jardim, além de abrigar ecossistemas frágeis ocupados por pequenos produtoresemregimedeagriculturafamiliar, apresenta diferentes paisagens, formas de uso e ocupação das terras. Em virtude de características geoambientais locais como relevo acidentado, solos com textura variável, características topográficas do relevo montanhoso e intenso regime pluviométrico, suas terras são consideradas de elevada vulnerabilidade aos processos erosivos como a movimento de massas e escorregamentos. Fatores que aliados à pressão de uso da terra, reduzida cobertura vegetal em certas áreas, atividades antrópicas não planejadas e, falta

Sociedade \& Natureza, Uberlândia, 22 (1): 55-73, abr. 2010 
Estudo Geoambiental do Município de Bom Jardim - RJ, com Suporte de Geotecnologias: Subsídios ao Planejamento de Paisagens

Rurais Montanhosas

Braz Calderano Filho, Helena Polivanov, Antônio José Teixeira Guerra, Cesar da Silva Chagas, Waldir de Carvalho Júnior,

Sebastião Barreiros Calderano

de alternativas técnicas apropriadas à realidade local, intensificam os processos erosivos e de perda de solo fértil, contribuindo para o avanço no estágio de degradação dos recursos (solo-água-biodiversidade).

A pressão de uso agrícola nestas áreas, tidas como marginais para o processo produtivo, compromete a capacidade de suporte dos sistemas naturais e expõe os recursos solos e água a maiores taxas de degradação (CALDERANO FILHO et al., 2007). Nesses casos, os distúrbios ambientais, vistos como indicadores de desajustes internos no sistema da paisagem, ampliam-se com a interferência humana, comprometendo a sustentabilidade ambiental (COELHO NETTO 1994).

Segundo Mateo (1997), o planejamento ambiental é um instrumento dirigido para programar o uso do território, as atividades produtivas, o ordenamento dos assentamentos humanos e o desenvolvimento da sociedade, em congruência com a vocação natural da terra, o aproveitamento sustentável dos recursos e a proteção e qualidade do meio ambiente. Sua execução envolve uma complexidade de parâmetros que incluem variáveis ecológicas, econômicas, sociais e políticas e tem, como propósito, manter a capacidade de sustentação dos ecossistemas e a proteção ambiental (MATEO, 1984, 1997).

A falta de informações básicas para dar suporte às demandas de planejamento, uso e manejo das terras, particularmente, nas áreas de relevo movimentado, com fortes limitações ao uso e severas restrições da legislação ambiental vigente, contribui para agravar ainda mais esse quadro (CALDERANO FILHO et al., 2006; 2007).

Em um processo de planejamento, o estudo da distribuição espacial dos elementos físicosbióticos componentes da paisagem, em escala adequada e compatível com as necessidades de comunidades rurais, torna-se uma ferramenta útil para o planejamento de uso e manejo dos recursos naturais, principalmente do solo e da água. A busca da sustentabilidade passa pelo conhecimento das variáveis ambientais no seu conjunto, no planejamento das atividades produtivas e na avaliação dos riscos ambientais (CALDERANO FILHO, 2003).

Esses estudos têm sido feitos de forma bastante variada e diferenciada, em função de aspectos relacionados à metodologia utilizada e aos objetivos da aplicação. Exemplos de trabalhos nessa linha são encontrados em Tricart \& Kiewitdejonge (1992); Witter et al., (1991; 1993); Witter (1993); Silva (1993); Schaefer (1997); Dantas (2001); Dias (2002); Calderano Filho (2003); Calderano (2005); Reckziegel \& Robaina (2006); Calderano Filho et. al. (2009a), entre outros.

Com base no exposto, os objetivos do trabalho foram produzir informações dos elementos físico-bióticos componentes da paisagem e, estudar as características geoambientais e uso da terra, visando fornecer subsídios para o planejamento geoambiental e a gestão sustentável das terras de paisagens rurais montanhosas na serra dos Órgãos, ocupadas com agricultura familiar. Para este fim, com suporte de geoprocessamento e SIGs, montou-se uma base de dados espaciais, composta de produtos de sensoriamento remoto, modelo digital de elevação (MDE) e mapas temáticos do meio físico de solos, relevo, geologia, vegetação, uso da terra, todos na escala 1:50.000, produzidos através de mapeamentos e prospecções campo, incluindo declividade e rede de drenagem. Associou a esta base, informações socioeconômicas, de pluviosidade, legislação ambiental e perfil tecnológico dos agricultores locais.

O uso de SGI em estudos ambientais, constituem atualmente tecnologia adequada para auxiliar na elaboração de propostas de manejo ambiental (TAGLIANI, 2002; CÂMARA et al., 2000; FOOTE \& HUEBNER, 1995).

Os procedimentos utilizados permitiram conhecer os recursos da terra, discriminar e caracterizar aspectos físicos e ecológicos dos elementos componentes da paisagem, distinguir áreas potencialmente agricultáveis, destinadas à preservação e recuperação ambiental e subsidiar a 
Estudo Geoambiental do Município de Bom Jardim - RJ, com Suporte de Geotecnologias: Subsídios ao Planejamento de Paisagens Rurais Montanhosas

Braz Calderano Filho, Helena Polivanov, Antônio José Teixeira Guerra, Cesar da Silva Chagas, Waldir de Carvalho Júnior,

Sebastião Barreiros Calderano

indicação de formas viáveis de exploração racional das terras, mais condizentes com a realidade local e com base nas vocações agroeclógicas das terras.

Os resultados aqui apresentados correspondem parte dos documentos cartográficos produzidos com o diagnóstico geoambiental para a área do município, como os mapas de solos, MDE, declividade, geologia e uso e cobertura das terras, incluindo a metodologia de trabalho e a descrição sucinta referente a cada tema. O estudo justificase como uma contribuição para o conhecimento e caracterização de áreas de ecossistemas fragilizados na serra dos Órgãos, ocupadas com agricultura familiar.

\section{MATERIAIS E MÉTODOS}

\section{1. Área de estudo}

O estudo foi desenvolvido nos domínios do município de Bom Jardim e área de entorno, região serrana do estado do Rio de Janeiro (FIGURA 1). Com aproximadamente de 48.469 .00 ha de área, engloba parte das seguintes folhas topográficas na escala 1:50.000, da Fundação Instituto Brasileiro de
Geografia e Estatística (FIBGE): Quartéis (SF-23Z-B-III-3), Cordeiro (SF-23-Z-B-III-1), Trajano de Morais (SF-23-Z-B-III-2) e Duas Barras (SF-23-ZB-II-2). O referido município inseri-se na unidade geomorfológica denominada "reverso das colinas e maciços costeiros do Planalto da Serra dos Órgãos", unidade definida pelo domínio predominante de morros elevados e montanhas, com ocorrência de alvéolos de relevo suave, subordinados ao domínio montanhoso (DANTAS, 2001).

O clima é do tipo tropical mesotérmico brando super úmido ou o mesotérmico úmido, com temperaturas elevadas bem distribuídas o ano todo e pouca ou nenhuma deficiência hídrica (NIMER, 1977; FAPERJ, 1980). O verão é brando, com temperatura média anual de $18{ }^{\circ} \mathrm{C}$ e mínima de 13 ${ }^{\circ} \mathrm{C}$ no inverno, sendo junho e julho os meses mais frios. A precipitação média anual, segundo dados da estação meteorológica de Bom Jardim, é de 1536 mm, concentrados no verão (ANA, 2007). O domínio florístico é a floresta ombrófila densa ou floresta tropical perenifólia e subperenifólia, caracterizadas por apresentar vegetação exuberante, com formação densa e espécies arbóreas de grande porte, típicas de clima úmido.

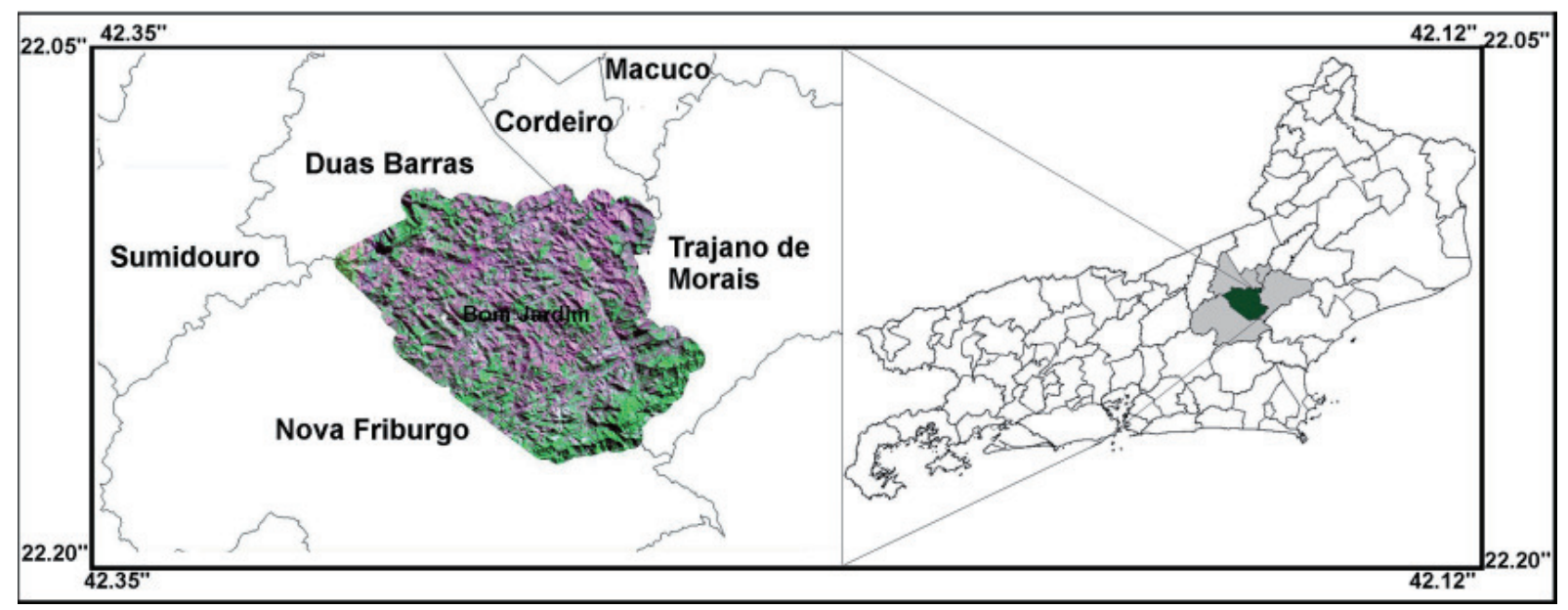

FIGURA 1: Localização da área de estudo (município de Bom Jardim), no contexto da região serrana do estado do Rio de Janeiro.

\subsection{Metodologia}

A metodologia adotada partiu da geração de dados básicos no campo através de mapeamentos temáticos do meio físico, e a operacionalização dos mesmos com a utilização de um SIG. A execução

Sociedade \& Natureza, Uberlândia, 22 (1): 55-73, abr. 2010 
do trabalho envolveu etapas de escritório, campo e laboratório e seguiu as seguintes fases: construção da base de dados geográficos em ambiente SIG, aquisição de dados primários e armazenamento desses dados em meio digital, via digitação na tela e determinações analíticas.

2.2.1. Aquisição de dados e materiais básicos utilizados

Foram utilizados os seguintes dados e materiais básicos: a) prospecções de campo para geração de mapas de solos, uso e cobertura das terras, na escala 1:50.000; b) dados de relevo, obtidos do Shuttle Radar Topography Mission (SRTM), do ASTER GDEM e das cartas planialtiméricas da FIBGE; c) fotografias aéreas pancromáticas de 1970 na escala 1:20.000, cedidas pelo DRM/RJ, (Departamento de Recursos Minerais); d) cartas topográficas da FIBGE na escala 1:50.000, folhas Quartéis (SF-23-Z-B-III-3), Cordeiro (SF-23-ZB-III-1), Trajano de Morais (SF-23-Z-B-III-2) e Duas Barras (SF-23-Z-B-II-2), com curvas de nível equidistantes de 20m; e) imagens Landsat ETM+ de outubro de 2000 , com resolução espacial de $30 \mathrm{~m}$ nas bandas 1 a 7 e resolução de $15 \mathrm{~m}$ na banda 8 , correspondente a órbita/ponto 216/075, disponível no site da UMIACS, (University of Maryland Institute for Advanced Computer Studies); f) imagens digitais CBERS CCD (órbita/ponto 151/125) de julho de 2004 e setembro de 2007, fornecidas gratuitamente pelo site do INPE (Intituto de Pesquisas Espaciais); e g) imagens ASTER.

As imagens CBERS foram registradas por bandas isoladamente, efetuando uma transformação geométrica que relaciona coordenadas de imagem (linha, coluna) com coordenadas de um sistema de referência geográfica, padronizando 20 pontos de controle e um erro médio quadrado (RMS) de 10, as imagens Landsat e ASTER já estavam no formato Geotif.

Todasasinformaçõescartográficasnecessárias foram preparadas em ambiente de geoprocessamento, gerando um banco de dados digitais no ArcGIS
Desktop 9.0, na projeção Universal Transversa de Mercator (UTM), fuso 23S e datum Córrego Alegre, com implementação de produtos de sensoriamento remoto e mapas temáticos produzidos. As fotografias aéreas em formato tif foram georreferenciadas, com auxílio do SIG , padronizando 10 pontos por foto e erro máximo aceitável de 10 (RMS). As cartas topográficas da FIBGE, foram unidas no SIG com relação aos planos de informação para compor a área de estudo. A seguir, foram editadas, extraindo em formato shape para a área de interesse os planos de informação de drenagem, limites, estradas, edificações, pontos cotados e curvas de nível. Numa etapa posterior, colocou-se a topologia nas curvas de nível, efetuaram-se os ajustes e eliminaram-se as informações inconsistentes, obtendo-se dessa forma, a base cartográfica digital na escala 1:50.000.

A seguir, foi elaborado o MDE da área, com resoluções espaciais de 15 e $30 \mathrm{~m}$, pelo interpolador topogrid (HUTCHINSON, 1989), utilizando o software Arc/Info, que emprega um método de interpolação especificamente projetado para criar modelos digitais do terreno hidrologicamente corretos. Para a geração do MDE, efetuaram-se ajustes topológicos e direcionais da hidrografia, das curvas de nível e dos pontos cotados. Com auxílio do software Arc/Info, a rede hidrográfica foi editada, obtendo-se uma rede de arcos simples, conectados e orientados na direção do escoamento. Da mesma forma, as curvas de nível foram ajustadas à hidrografia para assegurar sua coerência. Numa etapa de pós-processamento, procedeu-se a limpeza das depressões espúrias contidas no MDE. A partir do MDE corrigido e isento de depressões espúrias, foram elaborados os mapas de declividade da área e outras variáveis de interesse como direção do fluxo, fluxo acumulado, orientação das vertentes, perfil de curvatura, plano de curvatura e imagem de sombreamento do relevo, utilizandose o módulo 3D Analyst do ArcGIS Desktop 9.0. Estes mapas foram utilizados juntamente com os produtos de sensoriamento remoto como material cartográfico básico nas etapas de prospecções e mapeamentos de campo, delimitação de bacias de captação, verificação de limites entre unidades de 
Estudo Geoambiental do Município de Bom Jardim - RJ, com Suporte de Geotecnologias: Subsídios ao Planejamento de Paisagens Rurais Montanhosas

Braz Calderano Filho, Helena Polivanov, Antônio José Teixeira Guerra, Cesar da Silva Chagas, Waldir de Carvalho Júnior, Sebastião Barreiros Calderano

mapeamento, identificação de diferentes tipos de solos e pedoambientes.

\subsubsection{Modelos digitais de elevação}

Foram utilizados, neste estudo, três conjuntos distintos de MDEs. O primeiro gerado a partir de curvas de nível, o segundo obtido com os dados do ASTER GDEM e o terceiro obtido com os dados do SRTM. O modelo SRTM alcança precisão cartográfica até a escala 1:100.000 (SANTOS et. al., 2005). Em escala detalhadas, os dados degradam a precisão, ele foi testado assim mesmo. Na escala usada neste trabalho, o melhor resultado foi obtido com o MDE derivado do topogrid. Os MDEs do SRTM e do ASTER são disponibilizados gratuitamente nos sites http//srtm.csi.cgiar.org e http//imsweb.aster. erdasc.org.jp. Para compor as áreas de estudo, foram baixados os modelos do SRTM 30 e do ASTER GDEM, fornecidos no formato geotiff e datum WGS84. A seguir, foram criadas duas máscaras sendo recortada a área de interesse deste estudo. Os MDEs finais foram transformados para a projeção UTM, zona 23S e datum Córrego Alegre.

Foi realizada uma avaliação da qualidade dos MDEs em termos da representação dos aspectos da superfície, conforme sugerido por Hutchinson \& Gallant (2000) e Wise (2000), que são: a) análise do número e extensão das depressões espúrias; b) comparação entre a drenagem mapeada e a drenagem derivada pelos diferentes MDEs; c) comparação entre as curvas de nível derivadas e as curvas de nível originais; e d) análise das bacias de contribuição derivadas. De acordo com Hutchinson \& Gallant (2000), as curvas de nível derivadas de um MDE fornecem uma avaliação sensitiva sobre a estrutura do terreno e é bastante útil devido à sensibilidade aos erros de elevação na fonte de dados. Deste modo, foi realizada uma comparação visual entre as curvas de nível derivadas a partir dos MDEs com as curvas de nível originais. Neste procedimento, também foi utilizado o módulo Spatial Analyst do SIG.

De acordo com Fernandes \& Menezes (2005), o método baseado na rede interna de triangulação (TIN) para geração de MDE é bastante eficiente em áreas de relevo acidentado. No entanto, o módulo topogrid, que utiliza a hidrografia e outros corpos de água como elementos de descontinuidade e suavização, possibilita um sensível aumento da precisão dos modelos gerados (FERNANDES \& MENEZES, 2005).

\subsubsection{Diagnóstico}

A etapa de campo teve como objetivo o estudo "in loco" dos elementos componentes da paisagem com a execução do diagnóstico geoambiental. Para o diagnóstico, foram considerados parâmetros referentes ao relevo, declividade, erosão, drenagem, pedregosidade, rochosidade, vegetação original, transformações na paisagem, uso agrícola, solos, observações referentes à geologia, clima, características da vegetação e cobertura dos solos, ação da água nas encostas, perfil tecnológico dos agricultores locais e áreas de proteção legal, sendo que os detalhes julgados de interesse foram registrados fotograficamente. Os trabalhos de campo foram orientados para verificação da diversidade dos aspectos físicos, das atividades antrópicas e dos problemas de degradação e conflitos relacionados ao uso dos recursos naturais. Considerou-se também, o histórico socioeconômico e ambiental da região, de modo a fornecer um quadro geral da situação atual da área amostrada e o grau de conservação de seus habitats.

\subsubsection{Solos}

A prospecção e identificação dos solos foram executadas segundo o método de exame intensivo com intenso trabalho de campo e observações a pequenos intervalos, que permitiram visualizar a sequência de distribuição dos solos na paisagem e estabelecer a legenda preliminar. Estes serviços compreenderam a coleta de amostras de solo para posterior análise em laboratório, mapeamento com apoio nos produtos de sensoriamento remoto, MDE, sombreamento do relevo, declividade, curvas de nível, fotointerpretação de fotografias aéreas e observação das características das terras, levando- 
se em conta relevo, declividade, erosão, drenagem, pedregosidade, rochosidade e vegetação original, correlacionando esses fatores com a paisagem.

Devido a grande variação espacial, a pequenas distâncias em muitos dos atributos dos solos, foram coletados 30 perfis completos de solos, 31 amostras extras de horizontes A e $\mathrm{B}$ ou $\mathrm{B}$ e $\mathrm{C}$ e checados 456 pontos de campo. Os pontos de amostragem foram localizados de forma a representar as várias classes e tipos de solos que ocorrem na área. Os perfis coletados, distribuem-se por vários pontos da paisagem, não configurando topossequências, buscando desta forma, obter maior representatividade das diferentes situações fisiográficas, além de sua distribuição geográfica. Os pontos checados foram marcados com o GPS e posteriormente transferidos para a base digital. Com os resultados das análises das amostras enviadas ao laboratório, foi elaborada a legenda de identificação dos solos. As determinações analíticas seguiram o manual de métodos de análise de solo (EMBRAPA, 1979). Para as descrições morfológicas seguiu as normas e definições contidas em Embrapa (1988) e Lemos \& Santos (1996). A classificação dos perfis de solo seguiu o Sistema Brasileiro de Classificação de Solos (EMBRAPA, 2006).

\subsubsection{Geologia}

Foram utilizados os estudos geológicos de Matos et. al., (1980) e Rio de Janeiro (1982), folhas Cordeiro, Quartéis, Duas Barras e Trajano de Morais, fornecidas pelo Departamento de Recursos Minerais (DRM - RJ). As folhas adquiridas em meio digital no formato tiff, foram georreferenciadas e cortadas com auxílio de uma máscara, extraindo a área de cobertura do município. A seguir foi editado, no SIG, os shapes referentes aos polígonos das unidades dominantes, as linhas de falhas e os pontos de ocorrências, conforme a legenda constante nas cartas fornecidas.

\subsubsection{Uso atual e cobertura das terras}

O mapa de uso e cobertura das terras foi produzido através da aplicação conjunta da classificação supervisionada com suporte de fotografias aéreas, como auxílio na discriminação final. Com o uso do SPRING (Sistema de Processamento de Informações Georreferenciadas), a partir da imagem Landsat de 2000, bandas 2 a 7 , excluindo a banda 6 , gerou o mapa de uso, primeiramente por classificação supervisionada apoiado em trabalhos de campo sistemáticos para obtenção de amostras georreferenciadas com auxílio de GPS. O algoritmo para comparar as regiões da imagem com as classes que foram discriminadas, foi a distância de Battacharya. Todo o processo seguiu as seguintes etapas, imagem/segmentação/contexto/ extração de regiões e classificação. A segmentação consiste na extração de objetos relevantes para as aplicações desejadas.

Nesse mapa, as classes discriminadas foram floresta, afloramento de rocha, pastagem, cultivos, água, área urbana e mata com afloramentos. A classificação supervisionada foi validada com pontos de referência obtidos mediante trabalho de campo e interpretação de fotografias aéreas. $\mathrm{O}$ uso de fotografias aéreas como auxiliar à classificação supervisionada, facilita a separação nas áreas com dificuldades de discriminação na interpretação supervisionada. Assim, tanto na geração quanto na edição final deste mapa foi imprescindível a associação de atividades de campo prévias e de checagem, para ajustes e correções posteriores no mapa gerado. A carta de vegetação natural foi atualizada com informações de campo e delimitada junto com o mapa de uso e cobertura. Nos ajustes finais o mapa de uso busca contemplar todas as transformações em que o uso da terra alterou a vegetação original.

\subsubsection{Socioeconomia e outras informações}

Visando complementar os dados, coletaramse informações sobre as atividades socioeconômicas, áreas de proteção legal e levantados dados sobre a pluviosidade. $\mathrm{O}$ comportamento tecnológico e organizacional dos produtores rurais baseou-se nos dados e informações cedidos pela EMATER de Bom Jardim, no relatório do TCE - RJ e através de 
Estudo Geoambiental do Município de Bom Jardim - RJ, com Suporte de Geotecnologias: Subsídios ao Planejamento de Paisagens Rurais Montanhosas

Braz Calderano Filho, Helena Polivanov, Antônio José Teixeira Guerra, Cesar da Silva Chagas, Waldir de Carvalho Júnior, Sebastião Barreiros Calderano

conversas com alguns dos produtores da área, com o principal intuito de inferir o grau de modernização e o nível de conscientização e preocupação com as questões ambientais.

\subsubsection{Base de dados espaciais e SIGs}

A base cartográfica digital, contendo as curvas de nível, limites, drenagem, pontos cotados e infra-estrutura viária, foi usada primeiramente para gerar o MDE, Após isso, gerou-se o mapa de declividade e outras variáveis de interesse como direção do fluxo, fluxo acumulado, orientação das vertentes, perfil de curvatura, plano de curvatura e imagem de sombreamento do relevo. A seguir, foram incorporadas a essa base os mapas de solos, geologia, vegetação, uso e cobertura das terras e vegetação, produzidos com o diagnóstico geoambiental. Complementou-se a base de dados com as informações socioeconômicas, de pluviosidade e de áreas protegidas por legislação específica ou reservas existentes, constituindo assim, um conjunto de informações em meio digital, padronizadas na projeção UTM, fuso 23S e datum Córrego Alegre, necessárias ao SIG, para análises, cruzamentos e geração de novos mapas interpretativos úteis ao planejamento, os quais irão auxiliar na análise integrada e elaboração do planejamento geoambiental do município de Bom Jardim.

Foram utilizados os laboratórios do IGEO/ UFRJ (departamentos de Geologia e Geografia) e EmbrapaSolos, para a execução das etapas de geoprocessamento e uso dos SIGs. A entrada de dados foi feita via digitalização e escanerização, mediante a importação de arquivos. Utilizaramse os programas Arc/Info e ArcGIS Desktop 9.0, Spring 5.02, Photoshop 5.0, IrfanView e Excel, tanto para análises, cruzamentos e geração de mapas, como para armazenamento e manipulação de dados geocodificados e informações contidas na BDE. As fases seguidas com o uso do SIG podem ser divididas nos seguintes módulos: entrada de dados; armazenamento e gerenciamento da base de dados; interação; transformação e análises; exibição e saída de dados.

\section{RESULTADOS}

A área estudada apresenta um quadro fisionômico bastante diversificado, com relevo movimentado, típico de serra e um mosaico de paisagens e feições que foram sendo alteradas ao longo dos anos, devido às constantes e sucessivas intervenções antrópicas, em função de diferentes usos do solo. A substituição da floresta original por atividades agropecuárias imprimiu, ao cenário atual, uma paisagem de aspecto antrópico.

A classificação dos solo foi elaborada segundo os critérios contidos em (EMBRAPA, 2006). Asclasses definidas, com base nas características morfológicas, análises físicas, químicas e mineralógicas dos perfis coletados, de acordo com o mapa de solos (FIGURA 2), foram: Latossolos, compreendendo Latossolos Vermelho (LV), Latossolos Amarelos (LA) e Latossolos Vermelho-Amarelos (LVA). Argissolos, compreendendo Argissolos Amarelos (PA), Argissolos Vermelhos (PV), Argissolos Vermelho-Amarelos (PVA) e solos intergrades com a classe dos Latossolos. Cambissolos, compreendendo Cambissolo Háplico (CX) e Cambissolo Flúvico. Neossolos, compreendendo Neossolos Litólicos (RL) e Neossolos Flúvicos (RY) e como tipo de terreno os Afloramentos de rocha (AR). Essas classes com maior representatividade na área ocorrem como primeiro, segundo ou terceiro membro de associação. Em menor proporção, foram constatados Cambissolo Flúvico (CY), Cambissolo Húmico (CH) e Gleissolos Háplicos (GX), que ocorrem como inclusões nas unidades de mapeamento.

No $4^{\circ}$ nível categórico do SiBCS (EMBRAPA, 2006), as classes de solos foram subdivididas considerando-se o tipo de horizonte $\mathrm{A}$, características taxonômicas de natureza intermediária, fertilidade natural, grupamentos texturais, constituição macroclástica, tipos de vegetação classes de relevo e arranjados em várias unidades de mapeamento. $\mathrm{Na}$ FIGURA 2, é mostrado o mapa de solos da área. A TABELA 1 mostra a legenda sinótica de solos. Os Afloramento de Rocha constituem tipos de terrenos e foram separados em três unidades, (AR1 a AR3). Os

Sociedade \& Natureza, Uberlândia, 22 (1): 55-73, abr. 2010 
Estudo Geoambiental do Município de Bom Jardim - RJ, com Suporte de Geotecnologias: Subsídios ao Planejamento de Paisagens Rurais Montanhosas Braz Calderano Filho, Helena Polivanov, Antônio José Teixeira Guerra, Cesar da Silva Chagas, Waldir de Carvalho Júnior, Sebastião Barreiros Calderano

Latossolos Amarelos (LA), foram separados em oito unidades, (LAd1 a LAd8), os Latossolos Amarelos Húmicos (LAH), separados em seis unidades (LAdh1 a LAdh6), os Latossolos Vermelhos (LV), separados em cinco unidades, (LVd1 a LVd5), os Latossolos Vermelho-Amarelos (LVA), separados em oito unidades, (LVAd1 a LVAd8), os Argissolos Vermelhos (PV), separados em cinco unidades (PVd1 a PVd5), os Argissolos Vermelho-Amarelos (PV), separados em sete unidades, PVAd1 a PVAd7, o Argissolo Amarelo (PA), constitui uma única unidade (PAd1), os Cambissolos Háplicos (CX), separados em três unidades, (CXbd1 a Cxbd3), os Neossolos Litólicos e Neossolos Flúvicos são membros de associação.

As terras do município abrange os dois principais domínios fisiográficos regionais, as baixadas e as terras altas. Vários ambientes compõem a região estudada, mas de forma simplificada podese agrupá-los em três compartimentos distintos, relacionadas às feições geomorfológicas terras baixas e terras altas, ou seja, as elevações com encostas abruptas, constituídas por montanhas alinhadas e blocos rochosos salientes, com relevo montanhoso e escarpado; em posições intermediarias uma sequência de encostas e colinas íngremes ou onduladas margeadas por morros e circundadas por exposição rochosa, com relevo ondulado e forte ondulado e as baixadas, com várzeas reduzidas dos rios e córregos que drenam a área, de relevo plano e suave ondulado.

Os solos identificados manifestam variações em suas características morfológicas, físicas e químicas, condicionadas pelo clima, relevo, material de origem e posição que ocupam na paisagem (CALDERANO FILHO et al., 2009b).

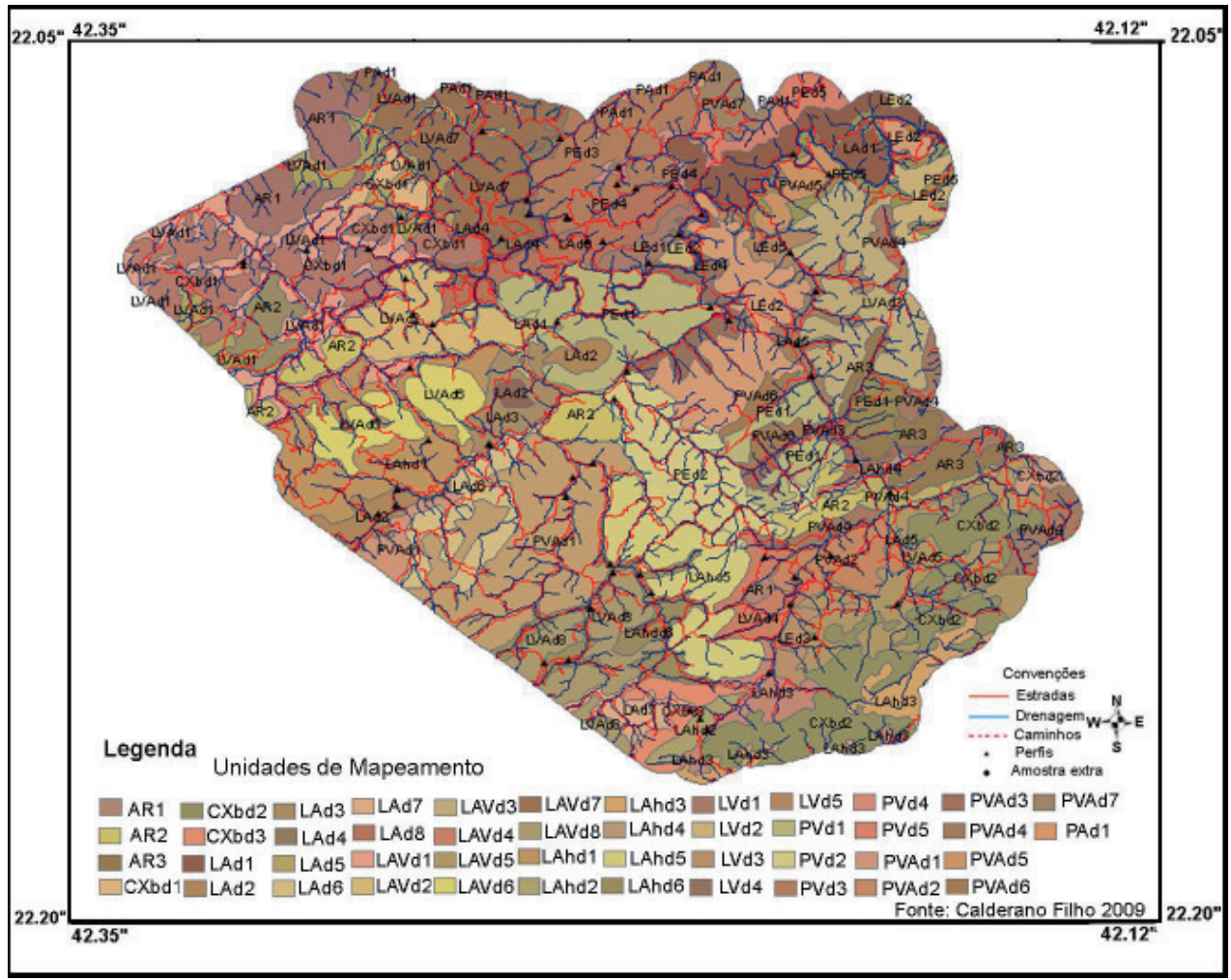

FIGURA 2: Mapa de solos do município de Bom Jardim, Rio de Janeiro.

Nas áreas de várzeas, importante para a recarga de aquíferos, predominam Neossolos Flúvicos distróficos, em pequenos diques marginais e terraços aluvionares do rio Grande e Cambissolos Flúvicos distróficos de rampas suaves, colúvioaluvionares e coluvionares. Em pequena proporção, 
Estudo Geoambiental do Município de Bom Jardim - RJ, com Suporte de Geotecnologias: Subsídios ao Planejamento de Paisagens Rurais Montanhosas

Braz Calderano Filho, Helena Polivanov, Antônio José Teixeira Guerra, Cesar da Silva Chagas, Waldir de Carvalho Júnior,

Sebastião Barreiros Calderano

foram identificados Gleissolos Háplicos distróficos, ocupando as partes mais baixas das várzeas. Nas terras altas, em posições intermediárias de relevo ondulado a forte ondulado, predominam os Argissolos Vermelhos e Vermelho-Amarelos, eventualmente Amarelos e Amarelos latossólicos, seguidos de Latossolos Amarelos e Latossolos Vermelhos, em menor proporção. Todos distróficos, apenas nos Argissolos Vermelhos há ocorrência de solos eutróficos, relacionados a diques de rochas básicas. Nas terras altas, constituídas por morros e montanhas alinhadas, de relevo forte ondulado a montanhoso, relacionadas com as litologias do PréCambriano, predominam os Argissolos Vermelhos e Vermelho-Amarelos, Latossolos Vermelhos e Latossolo Amarelo húmico, que gradativamente dão lugar a Cambissolos Háplicos e Húmicos e Neossolos Litólicos, todos distróficos, à medida que a vertente fica mais íngreme, (CALDERANO FILHO et al. 2009b). Os Latossolos húmicos tem maior ocorrência nas áreas abaciadas, de alvéolos intermontanos que compõem os domínios montanhoso e colinoso. Os afloramentos de rochas ocorrem em toda a área do município em diferentes posições da paisagem. Em alguns locais, os blocos rochosos e salientes elevamse a dezenas de metros acima do nível do terreno.

Foram associadas classes taxonômicas devido à ocorrência de variedade de solos com distribuição irregular pela área de estudo, o que impossibilitou sua delimitação cartográfica, em unidades simples. $\mathrm{Na}$ composição das associações, foi considerado, em primeiro lugar, o componente mais importante sob o ponto de vista de extensão, usando-se o mesmo critério para os demais componentes da associação.

TABELA 1. Legenda sinótica de solos.

\begin{tabular}{|c|c|c|c|c|c|c|c|c|}
\hline Símbolo & ha & $\%$ & Símbolo & ha & $\%$ & Símbolo & ha & $\%$ \\
\hline LAd1 & 1.076 & 2,22 & LVAd1 & 3.197 & 6,59 & PVAd1 & 2.943 & 6,10 \\
\hline LAd2 & 853 & 1,75 & LVAd2 & 974 & 2,00 & PVAd2 & 627 & 1,29 \\
\hline LAd3 & 555 & 1,14 & LVAd3 & 1.711 & 3,54 & PVAd3 & 292 & 0,60 \\
\hline LAd4 & 459 & 0,94 & LVAd4 & 538 & 1,11 & PVAd4 & 1.277 & 2,63 \\
\hline LAd5 & 571 & 1,18 & LVAd5 & 1591 & 3,28 & PVAd5 & 346 & 0,71 \\
\hline LAd6 & 926 & 1,92 & LVAd6 & 924 & 1,91 & PVAd6 & 313 & 0,65 \\
\hline LAd7 & 370 & 0,76 & LVAd7 & 1.771 & 3,66 & PVAd7 & 359 & 0,74 \\
\hline LAd8 & 966 & 1,99 & LVAd8 & 1.117 & 2,31 & & & \\
\hline Sub-total & 5.776 & 12,0 & Sub-total & 11.823 & 24,4 & Sub-total & 6.157 & 12,7 \\
\hline LAhd1 & 1.766 & 3,64 & LVd1 & 259 & 0,52 & PVd1 & 2.693 & 5,57 \\
\hline LAhd2 & 227 & 0,46 & LVd2 & 2.147 & 4,43 & $\mathrm{PVd} 2$ & 1.659 & 3,42 \\
\hline LAhd3 & 1.165 & 2,4 & LVd3 & 238 & 0,48 & PVd3 & 1.446 & 2,98 \\
\hline LAhd4 & 138 & 0,28 & LVd4 & 649 & 1,33 & PVd4 & 201 & 0,41 \\
\hline LAhd5 & 1.586 & 3,29 & LVd5 & 410 & 0,84 & PVd5 & 1.219 & 2,52 \\
\hline LAhdd6 & 890 & 1,83 & & & & & & \\
\hline Sub-total & 5.772 & 11,9 & Sub-total & 3.703 & 7,6 & Sub-total & 7.218 & 14,9 \\
\hline AR1 & 1.098 & 2,26 & CXbd1 & 1.898 & 3,91 & PAd1 & 247 & 0,5 \\
\hline AR2 & 1.240 & 2,55 & CXbd2 & 2.494 & 5,14 & & & \\
\hline AR3 & 676 & 1,39 & CXbd3 & 367 & 0,75 & & & \\
\hline Sub-total & 3.014 & 6.2 & Sub-total & 4.759 & 9.8 & Sub-total & 247 & 0,5 \\
\hline \multicolumn{5}{|c|}{ Total Geral } & 48.469 & \multicolumn{2}{|c|}{100,00} & \\
\hline
\end{tabular}

Sociedade \& Natureza, Uberlândia, 22 (1): 55-73, abr. 2010 
Estudo Geoambiental do Município de Bom Jardim - RJ, com Suporte de Geotecnologias: Subsídios ao Planejamento de Paisagens

Rurais Montanhosas

Braz Calderano Filho, Helena Polivanov, Antônio José Teixeira Guerra, Cesar da Silva Chagas, Waldir de Carvalho Júnior, Sebastião Barreiros Calderano

\subsection{Uso e Cobertura das Terras}

Originalmente coberta por vegetação florestal de Mata Atlântica, atualmente a vegetação encontra-se reduzida a alguns grupamentos florestais fragmentados e descaracterizados por sucessivas intervenções antrópicas (CALDERANO FILHO et al., 2009c). As transformações na paisagem deixou a vegetação original restrita às áreas de maiores altitudes. Nos trechos onde a floresta ocupava encostas e vales mais suaves, a vegetação encontrase bastante alterada ou foi completamente substituída por atividades agrícolas, como é o caso da mata ciliar.

A cobertura vegetal predominante em praticamente toda a área de estudo é de floresta tropical perenifólia e subperenifólia, caracteriza-se assim, por apresentar vegetação exuberante, com formações densa e espécies arbóreas de grande porte. Suas folhagens pouco se alteram durante o ano, mesmo nos meses de menor precipitação pluviométrica (EMBRAPA, 1980). Além destas formações, em ambientes de acumulação dos cursos d'água, sujeitos ou não a inundações periódicas, encontra-se vegetação apresentando originalmente fisionomia arbustiva ou herbácea, variável de acordo com a intensidade e duração da inundação, com ocorrência de floresta tropical subperenifólia de várzea. São encontrados também, campos antrópicos com pastagens, que estão dispersos por toda a região, culturas perenes, principalmente o café, e culturas anuais em menor escala. A FIGURA 3, mostra a distribuição das classes de uso do município.

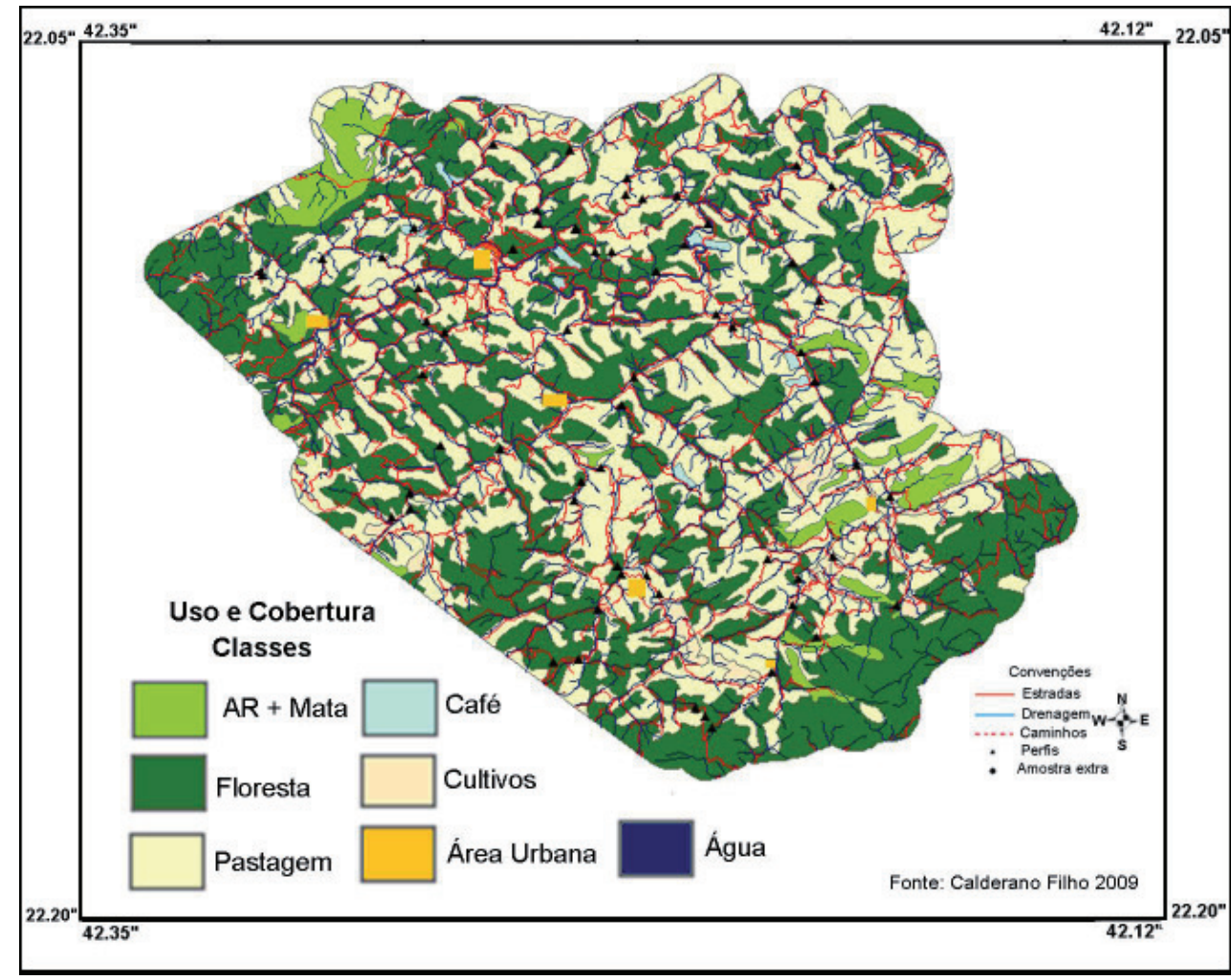

FIGURA 3: Mapa de uso e cobertura das terras do município de Bom Jardim, Rio de Janeiro.

No mapeamento de uso atual e cobertura das terras, procurou-se contemplar todas as transformações em que o uso da terra alterou a vegetação original, de modo a fornecer um quadro geral da situação atual da área amostrada. A agricultura é praticada nas encostas dos estreitos 
Estudo Geoambiental do Município de Bom Jardim - RJ, com Suporte de Geotecnologias: Subsídios ao Planejamento de Paisagens Rurais Montanhosas

Braz Calderano Filho, Helena Polivanov, Antônio José Teixeira Guerra, Cesar da Silva Chagas, Waldir de Carvalho Júnior,

Sebastião Barreiros Calderano

vales, até as cabeceiras de drenagem, em pequenos módulos rurais, típica de pequenos proprietários rurais, em regime de agricultura familiar. As terras do município são utilizadas predominantemente com pastagens, em geral de Braquiária, que ocupam 49 $\%$ da área, cultivos de olerícolas, plantios de café e de flores ornamentais, dentre as quais a principal é o plantio de rosas, além da pecuária de leite e corte.

Onde há exposição rochosa, nota-se uma camada de finíssima espessura, permitindo apenas a propagação de líquens, musgos e bromélias, e nos topos das rochas onde a declividade permite, acumula-se uma camada húmica rasa em contato direto com o substrato rochoso, ou associada a solos litólicos, favorecendo o aparecimento de vegetação de aspecto arbóreo. Nas várzeas, já modificadas pelo uso, predominam ciperáceas e vegetação rasteira. Aproximadamente $44 \%$ da área ainda encontramse preservados em matas. De maneira mais restrita, algumas áreas são utilizadas com reflorestamento de Eucaliptus. Para Oliveira et al., (1995), a maioria dos remanescentes da Mata Atlântica no estado do Rio de Janeiro são de matas secundárias em diferentes estágios sucessionais, alteradas pelas atividades agropecuárias ou exploração madeireira.
Neste mapeamento foi possível delimitar e discriminar as seguintes categorias de uso e cobertura: Remanescentes florestais, separados em Floresta, a qual representa as áreas que possuem cobertura vegetal arbórea densa, onde as copas se tocam. Tratase de vegetação secundária, evidenciado por um grau maior ou menor de alterações de sua composição original. Nessa escala, não foi possível fazer distinção cartográfica entre capoeiras e mata ciliar. A classe Pastagem engloba as áreas de pastagens plantadas e naturais, com diferentes níveis de manejo. A classe Afloramento + Mata Rala engloba vegetação de porte arbóreo arbustivo sobre afloramentos. Alguns fragmentos de vegetação rasteira muito pequenos que ocorrem nas partes altas, recobrindo os afloramentos com líquens, musgos e bromélias, estão aí incluídos. Cultivos englobam várias culturas com destaque para olerícolas e plantio de flores ornamentais. Tais culturas ocupam áreas muitos pequenas para serem mapeadas individualmente. Café corresponde a plantios de café Conilom e Arabica de idades variadas. Água representa toda superfície líquida, rios e lagos. Área Urbana representa as áreas edificadas. Áreas pontuais como reflorestamento de eucaliptos e áreas de solo exposto não foram possíveis de separar, considerando que estes, assim como as áreas de cultivo agrícola, ocorrem em pequenos módulos. A TABELA 2 mostra a distribuição das classes de uso e cobertura das terras.

TABELA 2. Percentuais das classes de uso.

\begin{tabular}{|l|c|c|l|r|c|}
\hline \multicolumn{1}{|c|}{ Categorias de Uso } & ha & $\mathbf{\%}$ & \multicolumn{1}{c|}{ Categorias de Uso } & ha & \% \\
\hline Floresta & 21.275 & 44 & Cultivos & 1.002 & 2,1 \\
\hline Pastagem & 23.754 & 49 & Café & 227 & 0,6 \\
\hline Ar + Mata & 2.102 & 4,0 & Água & 52 & 0,1 \\
\hline Área Urbana & 57 & 0,2 & \multicolumn{5}{|c|}{$\mathbf{4 8 . 4 6 9 . 0 0}$} \\
\hline Total & \multicolumn{7}{|c|}{} \\
\hline
\end{tabular}

$\mathrm{Na}$ região as formações naturais caracterizadas por florestas secas são muito variadas no que concerne à sua estrutura e composição, embora se relacionem com as florestas ombrófilas regionais, possuem designação própria, pois o ritmo estacional se traduz por avançado grau de deciduidade foliar durante a seca. A intensidade da queda das folhas depende da severidade da seca e/ou das condições edáficas existentes, só havendo deciduidade completa em casos extremos (RIZZINI, 1972). 
Estudo Geoambiental do Município de Bom Jardim - RJ, com Suporte de Geotecnologias: Subsídios ao Planejamento de Paisagens

Rurais Montanhosas

Braz Calderano Filho, Helena Polivanov, Antônio José Teixeira Guerra, Cesar da Silva Chagas, Waldir de Carvalho Júnior, Sebastião Barreiros Calderano

\subsection{Relevo}

O relevo da área foi estudado mediante os seguintes componentes: MDE, sombreamento de relevo e declividade. As FIGURAS 4 e 5 mostram o MDE e o mapa de declive da área.

O mapa de declividade foi classificado em seis classes de relevo: plano $(0-3 \%)$, suave ondulado $(3-8 \%)$, ondulado $(8-20 \%)$, forte ondulado $(20-$ $45 \%)$, montanhoso ( $45-70 \%)$ e escarpado $(>70 \%)$.
A definição de intervalos de classes de declives utilizadas está de acordo com as características morfoestruturais da área, a escala de trabalho, o interesse de precisão e os objetivos propostos.

O mapa de declividade, junto com as feições identificadas na fotointerpretação, serviu entre outros fins, para apoiar a cartografia dos solos no campo. Desta forma, o delineamento das unidades de mapeamento superpõe-se às classes de declives especificadas no mapa.

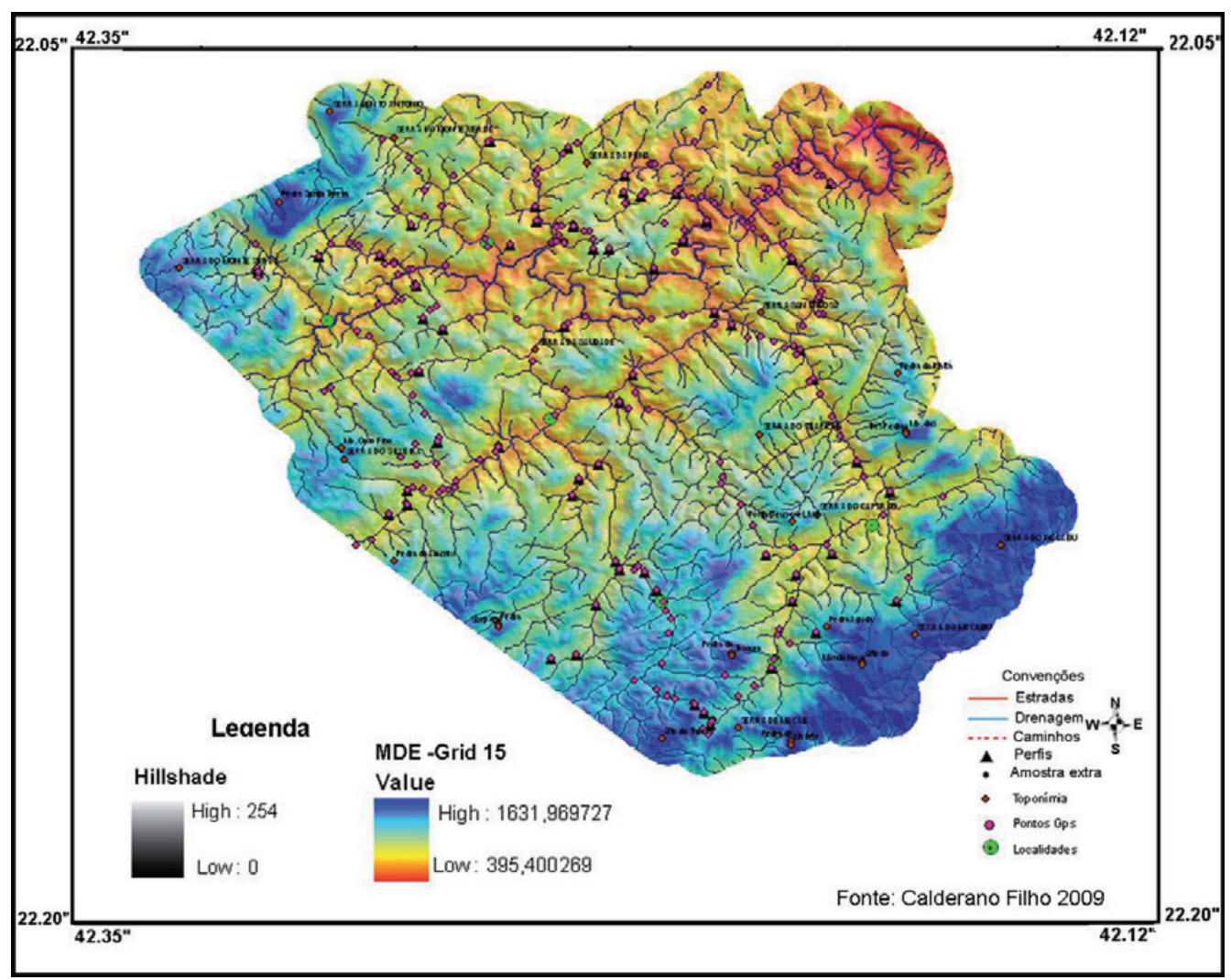

FIGURA 4: Modelo digital de elevação do município de Bom Jardim, Rio de Janeiro. 


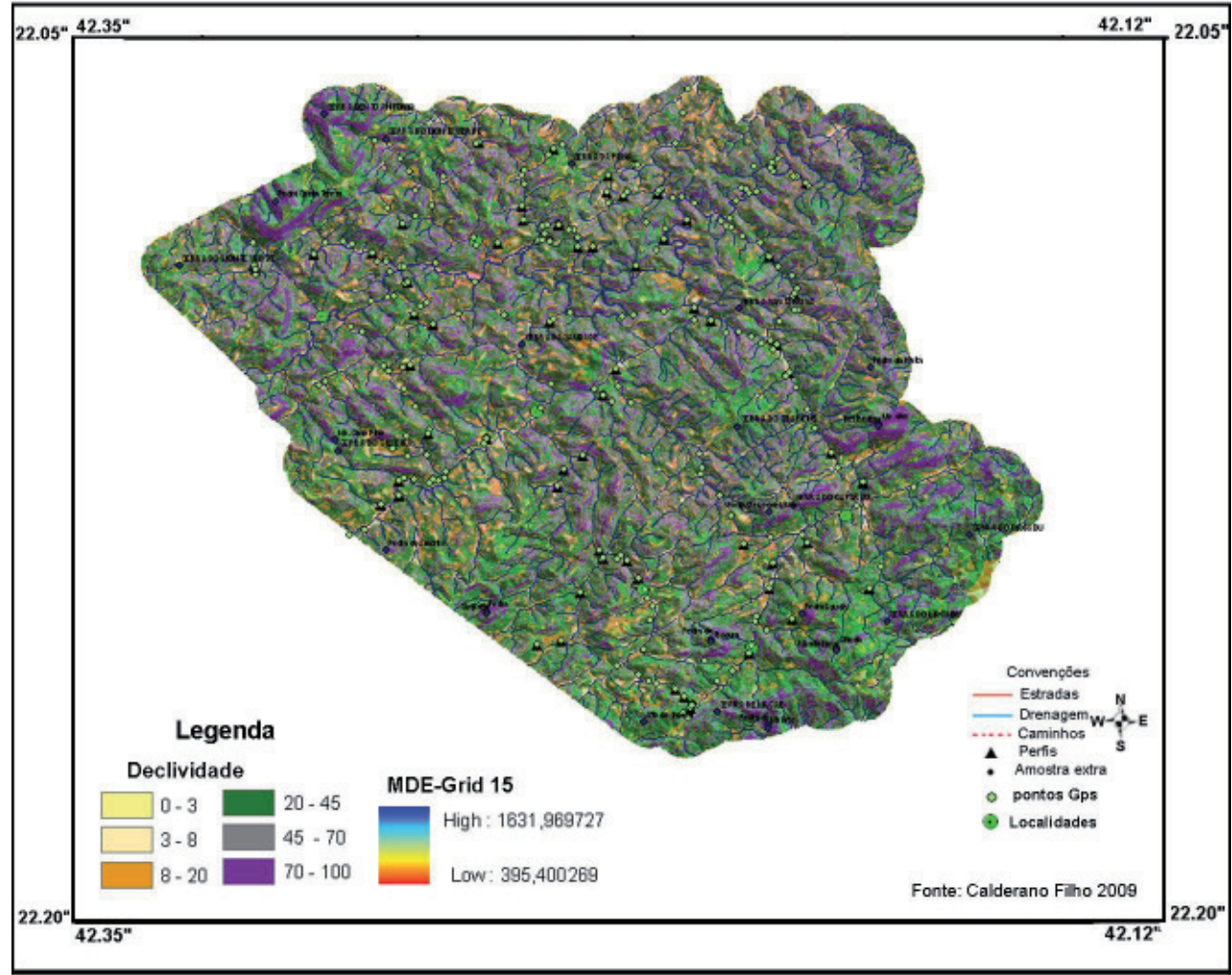

FIGURA 5: Mapa de declividade do município de Bom Jardim, Rio de Janeiro.

\subsection{Aspectos geológicos e material originário dos} solos

Estudos geológicos de Matos et al., (1980); Rio de Janeiro (1982); Mendes et al., (2004; 2002; 2007), assinalam para o município a predominância de um conjunto de ortognaisses e migmatitos do Complexo Rio Negro, associados aos ortognaisses granodioríticos do Batólito Serra dos Órgãos; leucognaisses e rochas metassedimentares do Grupo
Paraíba do Sul; e rochas ígneas de composição granodiorítica a granítica, mais raramente gabróica, que intrudem estas unidades. Com base nas cartas geológicas de Matos et al., (1980), extraiu-se com auxilio de SIG a área de interesse deste estudo. Foram utilizados neste trabalho apenas os dados referentes à litologia, os dados referentes às estruturas geológicas (dobras, falhas, fraturas, etc.) não estavam disponíveis. 


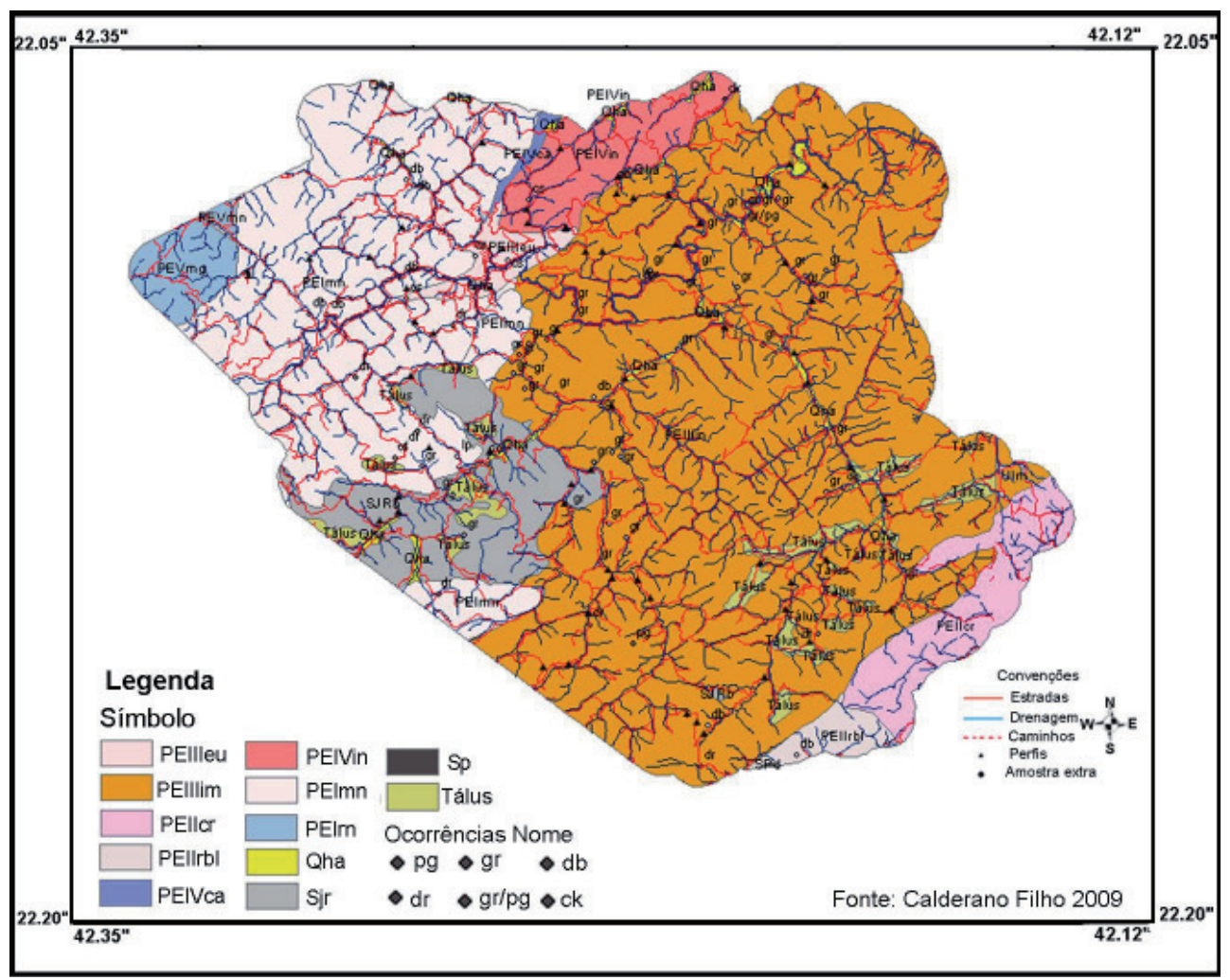

FIGURA 6: Mapa de geologia do município de Bom Jardim, Rio de Janeiro.

Matos et al., (1980), separam no município de Bom Jardim e adjacências os terrenos do préCambriano em quatro complexos, distribuídos em várias unidades, além de rochas da Associação Paraíba do Sul, constituídas de maciços graníticos Tardi a Post-tectônicos (em relação ao Ciclo Brasiliano), diques de gabro e giabásio que aparecem cortando praticamente todas as unidades do Pré-Cambriano, terrenos do quaternário holoceno e várias ocorrências litológicas, sem expressão cartográfica, como mostra a FIGURA 6. A planície fluvial e os terraços, onde ocorrem os sedimentos do Quaternário ocupam 801 ha. Com apenas $1,65 \%$, nas áreas de sopé, ocorrem os depósitos de tálus que ocupam 1216ha, com $2,52 \%$. O restante das unidades são mostradas na TABELA 3.

TABELA 3: Distribuição das unidades geológicas que ocorrem na área.

\begin{tabular}{|l|r|r|l|r|r|}
\hline \multicolumn{1}{|c|}{ Unidades } & \multicolumn{1}{c|}{ ha } & \multicolumn{1}{c|}{$\mathbf{1}$} & \multicolumn{1}{c|}{ Unidades } & \multicolumn{1}{c|}{ ha } & \% \\
\hline PEImn (Monerá) & 10.917 & 22,5 & PEIIIeu (Euclidilândia) & 651 & 1,3 \\
\hline PEIVin (Complexo Indiviso) & 1.762 & 3,6 & PEIIcr (Crubixais) & 2.079 & 4,3 \\
\hline PEIrn (Complexo Rio Negro) & 973 & 2,0 & Sjr (Granito S.JRibeirão) & 3.095 & 6,4 \\
\hline PEIVca (Capim Angola) & 122 & 0,2 & Sp (Granito SãoPedro) & 6,0 & 0,15 \\
\hline PEIIIim (Imbé) & 26.324 & 54,3 & Qha (Aluvião) & 801 & 1,65 \\
\hline PEIIrbl (Rio Bonito- Lumiar) & 523 & 1,1 & Tálus (Tálus) & 1.216 & 2,5 \\
\hline Total & & $\mathbf{4 8 . 4 6 9 . 0 0}$ & $\mathbf{1 0 0 , 0 0}$ \\
\hline
\end{tabular}


A várzea apresenta relevo plano, com 0 a $3 \%$ de declive, em certos locais o relevo é suave ondulado, com 3 a $8 \%$ de declive e a várzea é entulhada observando-se variações de altitude e natureza dos sedimentos. A drenagem no ambiente de várzea é impedida, com solos imperfeitamente drenados. Os vales são estreitos com vertentes de altitudes diferenciadas e relevo acidentado típico da serra do Mar. Compreende parte da bacia do médio alto curso do rio Grande, um dos formadores do rio Dois Rios, que aumenta seu fluxo ao receber as águas do rio Bengala e tributários, dos ribeirões São José, São Domingos, Santo Antônio e do córrego Barra Alegre, seus tributários e coletores de águas na área. Esses cursos d'água são os principais receptores de sedimentos carreados das encostas e levados até o rio Grande. A cota mais baixa de $480 \mathrm{~m}$ circunda o médio curso do rio Grande e a mais alta, de 1620 $\mathrm{m}$, delimita os divisores d'água nas cabeceiras dos ribeirões Santo Antônio e Pito Aceso, próximo ao Alto do Mundo Novo.

Os solos nas partes altas, no geral são bem drenados, mas observa-se, em pequenas porções de anfiteatro e áreas de depósitos de tálus, solos imperfeitamente drenados. Os blocos rochosos e salientes apresentam-se como enormes blocos que se destacam nos pontos mais proeminentes da topografia, a dezenas de metros acima do vale regional, com aspecto de montanha desnuda sujeita à esfoliação, apresentando sulcos, onde se fixa a vegetação rasteira de liquens, musgos e bromélias. $\mathrm{O}$ paredão descoberto muito raramente tem continuidade até o fundo do vale.

O material de origem dos solos é bastante diferenciado; os solos das encostas e partes mais altas têm origem essencialmente em produtos de alterações das rochas citadas e, em material de cobertura pseudo-autóctone influenciando até o desenvolvimento do horizonte B. Ocorre na área, extensão razoável de encostas coluviais de material transportado em fases diversas, em mistura com produtos da alteração das rochas acima citadas. $\mathrm{Na}$ várzea, o material é constituído de sedimentos argilo- arenosos, compreendendo aluviões fluviais recentes e formações aluviais e coluviais mais antigas do Holoceno, proveniente de material carreado das encostas e depositado nas calhas dos rios e córregos. Em certos locais, nota-se o aporte recente de material coluvial.

\section{CONCLUSÕES}

O primeiro resultado alcançado foi a base de dados georreferenciada contendo os mapas de solos, geologia, declividade, uso e cobertura das terras, suscetibilidade dos solos à erosão, MDEs e produtos de sensoriamento remoto, em que os mapas estão associados as suas respectivas tabelas com as características de seus atributos. Também foram contabilizadas, para os mapas temáticos, suas respectivas áreas em hectare e seus percentuais de ocorrência. Com relação aos MDEs, o modelo produzido pelo topogrid foi o que se mostrou mais coerente com a realidade do campo e o que melhor atendeu às expectativas do trabalho, na escala 1:50.000. Os modelos extraídos do SRTM e do ASTER GDM, embora constem do banco de dados, não foram aqui apresentados.

Os produtos gerados com diagnóstico geoambiental permitiram conhecer as propriedades e atributos dos elementos físicos e bióticos da paisagem, possibilitando avaliar as potencialidades e limitações de cada componente, com base nas ofertas ecológicas apresentadas, como planejar o uso e manejo dos recursos disponíveis com base na realidade local, além de contribuir para elaboração de um plano de manejo conservacionista da área.

O uso desses procedimentos, além de oferecer facilidades e rapidez na análise ambiental por integrarem dados numa mesma projeção e datum, armazenados em SIG, facilita a análise integrada da paisagem, possibilita maior precisão nas práticas de uso, manejo e conservação do solo, na busca de ações sustentáveis, além de contribuir para o conhecimento de ecossistemas fragilizados na Serra dos Órgãos, ocupados com agricultura familiar. 
Estudo Geoambiental do Município de Bom Jardim - RJ, com Suporte de Geotecnologias: Subsídios ao Planejamento de Paisagens

Rurais Montanhosas

Braz Calderano Filho, Helena Polivanov, Antônio José Teixeira Guerra, Cesar da Silva Chagas, Waldir de Carvalho Júnior, Sebastião Barreiros Calderano

\section{REFERÊNCIAS}

ANA. Agencia Nacional de Águas. Hidro Sistema de Informações Hidrológicas. Brasília: Superintendência de Informações Hidrológicas (SIH), 2007. Disponível em: <www.ana.gov.br $>$. Acesso em: 01 abr 2007.

CALDERANO FILHO, B. Visão sistêmica como subsidios para o planejamento agro-ambiental da microbacia do córrego Fonseca. 2003, 240f. Dissertação (Mestrado em Geografia) Departamento de Pós-Graduação em Geografia, Universidade Federal do Rio de Janeiro, Rio de Janeiro/RJ, 2003.

CALDERANO FILHO, B.; PALMIERI, F.; GUERRA, A.J.T.; ARGENTO, M.S.F.; CORREIA, J.R. Avaliação da aptidão agroecológica das terras da microbacia do córrego Fonseca, RJ. In: CONGRESSO BRASILEIRO DE MANEJO E CONSERVAÇÃO DO SOLO E DA ÁGUA, 16, Aracaju, SE. Anais... Viçosa: Sociedade Brasileira de Ciência do Solo, 2006.

CALDERANO FILHO, B.; GUERRA, A.J.T.; PALMIERI, F.; CORREIA, J.R.; ARGENTO, M.S.F. Aptidão agroeológica de terras, proposta de avaliação em paisagens rurais montanhosas da Serra do Mar, ocupadas por pequenos agricultores. Cadernos de C\&T, v. 24, Brasília, 2007.

CALDERANO FILHO, B.; ANDRADE, A.G.; POLIVANOV, H.; GUERRA, A.J.T.; Diagnóstico geoambiental da área do entorno do reservatório da Usina Hidrelétrica de Tombos, para fins de recuperação de áreas degradadas. Caminhos de Geografia, v. 10, n. 29, 2009a. p. 118 - 134.

CALDERANO FILHO, B.; POLIVANOV, H.; CARVALHO JÚNIOR, W.; GUERRA, A.J.T.; CHAGAS, C.S.; CLADERANO, S.B. Caracterização dos solos do município de Bom Jardim - RJ, com suporte de MDE e variáveis morfométricas. In: CONGRESSO BRASILEIRO DE CIÊNCIA DO SOLO, 32., Fortaleza, CE. Anais... Viçosa: Sociedade Brasileira de Ciência do Solo, p. 1060. 2009 b.
CALDERANO FILHO, B.; POLIVANOV, H.; CARVALHO JÚNIOR, W.; GUERRA, A. J. T.; CHAGAS. C.S.; CLADERANO, S.B. Diagnóstico físico-biótico do município de Bom Jardim - RJ, com auxílio de geotecnologias, para fins de planejamento de paisagens rurais montanhosas. In: CONGRESSO BRASILEIRO DE CIÊNCIA DO SOLO, 32, Fortaleza, CE. Anais... Viçosa: Sociedade Brasileira de Ciência do Solo, 2009c.

CALDERANO, S.B. Delineamento geoambiental do município de Santo Antônio de Pádua. 2005. 148f. Dissertação (Mestrado em Geologia) - Departamento de Pós-Graduação em Geologia,Universidade Federal do Rio de Janeiro, Rio de Janeiro/RJ, 2005.

CÂMARA, G.; MONTEIRO, A.M.V.; MEDEIROS, J.S. Representações Computacionais do Espaço: Um Diálogo entre a Geografia e a Ciência da Geoinformação. São José dos Campos, Divisão de Processamento de Imagens, Instituto Nacional de Pesquisas Espaciais (DPI/INPE) - 2000.

COELHO NETTO, A.L. Hidrologia de encostas na interface com a geomorfologia. In: GUERRA, A.J.T.; CUNHA, S.B. Geomorfologia: uma Revisão de Conceitos e Bases. Ed. Bertrand, Cap. 3, 1994. p. $93-148$.

DANTAS, M. E. Geomorfologia do Estado do Rio de Janeiro. In: CPRM. Serviço Geológico do Brasil. Rio de Janeiro: geologia, geomorfologia, geoquímica, geofísica, recursos minerais, economia mineral, hidrogeologia, estudos de chuvas intensas, solos, aptidão agrícola, uso e cobertura do solo, inventário de escorregamentos, diagnóstico geoambiental. Rio de Janeiro: CPRM: Embrapa Solos; [Niterói]: DRM - RJ, 2001. 1 CD - ROM.

DIAS, C.T.H.; FERNANDES FILHO, E. I.; SCHAEFER, C. E. R.; FONTES, L. E. F.; VENTORIM, L.B. Geoambientes do Parque Estadual do Ibitipoca, município de Lima Duarte MG. Revista Arvore, v. 26, n. 6, 2002. p. $777-786$. 
Estudo Geoambiental do Município de Bom Jardim - RJ, com Suporte de Geotecnologias: Subsídios ao Planejamento de Paisagens Rurais Montanhosas

Braz Calderano Filho, Helena Polivanov, Antônio José Teixeira Guerra, Cesar da Silva Chagas, Waldir de Carvalho Júnior,

Sebastião Barreiros Calderano

EMBRAPA. Serviço Nacional de Levantamento e Conservação de Solos. Manual de Métodos de Análise de Solo. 1 v. Rio de Janeiro, 1979.

EMBRAPA. Serviço Nacional de Levantamento e Conservação de Solo. Levantamento semidetalhado e aptidão agrícola dos solos do município do Rio de Janeiro, RJ. Rio de Janeiro, 1980. (EMBRAPA SNLCS. Boletim Técnico, 66).

EMBRAPA. Serviço Nacional de Levantamento e Conservação de Solos. Definição e notação de horizontes e camadas do solo. 2.ed. rev. atual. Rio de Janeiro, 1988. (EMBRAPA - SNLCS. Documentos, $3)$.

EMBRAPA. Centro Nacional de Pesquisa de Solos. Sistema Brasileiro de Classificação de Solos. Rio de Janeiro: Embrapa - CNPS; Brasília, DF: Embrapa SPI, 2006.

FAPERJ. Anuário Estatístico do Estado do Rio de Janeiro. Fundação de Amparo à Pesquisa do Estado do Rio de Janeiro, Rio de Janeiro, 1980.

FERNANDES, M.C.; MENEZES, P.M.L. Comparação entre métodos para geração de MDE para a obtenção de observações em superfície real no maciço da Tijuca - RJ. Revista Brasileira de Cartografia, v. 57, 2005. p. $154-161$.

FOOTE, E.K.; HUEBNER, D.J. Error, Accuracy and Precision. Austin, Department of Geography, University of Texas, 1995.

HUTCHINSON, M.F. A new method for gridding elevation and streamline data with automatic removal of pits. Journal of Hydrology, v. 106, 1989. p. 211 232.

HUTCHINSON, M.F.; GALLANT, J.C. Digital elevation models and representation of terrain shape. In: WILSON, J.P.; GALLANT, J.C. (Ed.). Terrain Analysis: Principles and Applications. New York: John Wiley \& Sons, 2000, p. 29 - 50.
LEMOS, R.C.; SANTOS, R.D. Manual de Descrição e Coleta de Solo no Campo. Campinas: Sociedade Brasileira de Ciência do Solo, 3 ed., 83 p., 1996.

MATEO, J.M.R. Apuntes de Geografia de Los paisages. Habana, Univerdidad de la Habana Facultad de Geografia, Editorial ENPES, 1984, 324 p.

MATEO, J.M.R. Planejamento ambiental: bases conceituais níveis e métodos In: CAVALCANTI, A.P.B. et.al. (Org.). Desenvolvimento Sustentável e Planejamento. Bases Teóricas e Conceituais. Fortaleza; Imprensa Universitária Fortaleza, 1997.

MATOS, G.; FERRARI, P.; CAVALCANTI, J. Projeto Faixa Calcaria Cordeiro - Cantagalo. Belo Horizonte: DNPM/CPRM, 1980.

MENDES, J.C.; JUNHO, M.C.B.; GHIZI, A. Geology and geochemistry of granitic and dioritic rocks of the São José do Ribeirão intrusive massif, mountain region of Rio de Janeiro State, Brazil. Revista Universidade Rural. Série Ciências Exatas e da Terra, v. 21, n. 2, 2002. p. 1 - 11.

MENDES, J.C.; JUNHO, M.C.B.; GHIZI, A. Diorites and hornblendite enclaves at Sumidouro, RJ, central Ribeira belt. Revista Brasileira de Geociências, v. 34, n. 1, p. $79-86,2004$.

MENDES, J.C.; TEIXEIRA, P.A.D.; MATOS, G.C.; LUDKA, I.P.; MEDEIROS, F.F.; ÁVILA, C.A. Geoquímica e geocronologia do granitóide Barra Alegre, faixa móvel Ribeira, Rio de Janeiro. Revista Brasileira de Geociências, v. 37, 2007. p. $101-113$.

NIMER, E. Clima. In: IBGE. Geografia do Brasil. Região Sudeste. Rio de Janeiro: IBGE, v. 3, 1977. p. $51-89$.

OLIVEIRA, R.R.; LIMA, D.F.; DELAMÔNICA, P.; TOFFOLI, D.D. \& SILVA, R. F. Roça caiçara: um sistema primitivo auto-sustentável. Ciência Hoje, 18 (104), 1995. p. $44-51$.

Sociedade \& Natureza, Uberlândia, 22 (1): 55-73, abr. 2010 
RECKZIEGEL, E.W.; ROBAINA, L E.S. Mapeamento geoambiental da área interfluvial dos rios Ibicuí e Jaguari - São Vicente do Sul, Ciência e Natura, v. 30, n. 2, 2008. p. $185-200$.

RIO DE JANEIRO (Estado). Secretaria de Estado de Indústria, Comércio e Turismo Departamento de Recursos Minerais. DRM, Projeto Carta Geológica do Estado do Rio de Janeiro. Folhas: Duas Barras e Trajano de Morais. 1982.

RIZZINI, C.T. Árvores e Madeiras Úteis do Brasil: Manual de Dendrologia Brasileira. São Paulo: Editora da USP, 1972. 294 p.

SANTOS, P.R.A.; GABOARDI, C.; OLIVEIRA, L.C. de. Avaliação da precisão vertical dos modelos SRTM para a Amazônia. Revista Brasileira de Cartografia, n. 58/01, abr. 2006, p. $101-107$.

SCHAEFER, C.E.R. Ecogeography and human scenario. Ciência e Cultura, v. 49, n. 4, 1997. p. 241 -252 .

SILVA, F.R.R. Zoneamento agroecológico do Nordeste: diagnóstico do quadro natural $e$ agrossocioeconomico. Petrolina: EMBRAPA/ CPATSA; Recife: EMBRAPA/CNPS, v. 1, 1993.

TAGLIANI, C.R.A. Técnica para avaliação da vulnerabilidade ambiental de ambientes costeiros utilizando um sistema geográfico de informações. Disponível em: $<$ http//www.fatorgis.com. br/11/2002/galeria de artigos acadêmicos $>$. Acesso em: 01 ago 2003.

TRICART, J.; KIEWITDEJONGE, C. Ecogeography and Rural Management. Harlowl: Longman Scintific, 1992.

WITTER, K.P.; CALDERANO FILHO, B.; AMARAL, F.C.S.; TAVARES, N.P.; CONCEIÇÃO, M. Zoneamento agroecológico dos municípios que compõem os vales dos rios Una, Macaé e São João, a leste do Estado do Rio de Janeiro. In: CONGRESSO BRASILEIRO DE CIÊNCIA DO SOLO, 23, 1991,
Porto Alegre, RS. Anais... Viçosa: SBCS, 1991, p. 265.

WITTER, K.P.; CALDERANO FILHO, B.; FONSECA, O.O.M.; FAGUNDES, S.R.F.; TAVARES, N.P.; VASCONCELOS, J.B.; MUELER, K.E.; ARANOVIK, S.; TAVARES, A.M.S.; DAMAZIO, H.N. Zoneamento agroecológico do Estado do Rio de Janeiro. Escala 1:250.000. In: CONGRESSO BRASILEIRO DE CIÊNCIA DO SOLO, 24, 1993, Goiânia GO. Anais... Viçosa: SBCS, 1993a, p. $413-414$.

WITTER, K.P. Solos, o mapa da mina. Globo Rural, v. 8,1993 . p. $30-33$.

WISE, S. Assessing the quality for hydrological applications of digital elevation models derived from contours. Hydrological Processes, v. 14, 2000. p. $1909-1929$. 